\title{
On Lunar Periodicity in Spawning of normally grown Falmouth Oysters (0. edulis) in 1925, with a comparison of the spawning capacity of normally grown and dumpy Oysters.
}

\author{
By
}

J. H. Orton, D.Sc.

Senior Naturalist at the Plymouth Laboratory.

With 7 Figures in the Text.

CONTENTS.

Introduction . . . . . . . . . . 199

Comparison of the characters of normal, dumpy, and slightly dumpy oysters $\quad 200$

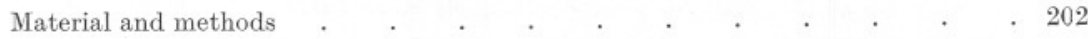

The comparative spawning capacity of normal and dumpy oysters from a general review of the observations made . $\quad$. $\quad$. . . . . . . . 204

Periodicity in the spawning habits . . . . . . . . . . . 206 206

Favourable weather for spawning in 1925 . $\quad . \quad$. $\quad$. . . . . . . . 206

Description of the Truro oyster beds and discussion regarding the biological simi-

larity of the population examined . . . . . . . . 207

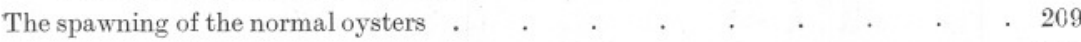

The spawning of the dumpy oysters . . . . . . . . . . 214

The period of incubation of oyster larvæ in the sea . . . . . . . . 216

Discussion on the probable causes of the periodicity in the spawning of the oyster . 218

On the frequency in and proportion of the oyster population spawning . . . 219

Other marine animals spawning at or near full moon . . . . . . . . . 221

Ancient naturalists on the condition of the oyster in relation to the moon's phases . 221

The economic aspect of the results obtained . . . . . . . . 222

Acknowledgments . . . . . . . . . . . . 223

Summary . . . . . . . . . . . . . . . . . 223

Literature . . . . . . . . 225

\section{INTRODUCTION.}

In a report on a survey of the oyster beds in the Fal Estuary (1) it was shown that even in the depleted condition of those beds $42 \%$ of the stock of oysters consisted of a type of oyster called dumpy. The percentage of these dumps is slightly greater, about $45 \%$, in the small oysters, which are not allowed to be taken from the beds. It was pointed out in that 
report that it would be worth while finding out whether this type of oyster is useful or not for breeding purposes : if dumpy oysters do not spawn in reasonable numbers in comparison with normal oysters, it would benefit the dredgermen to be allowed to take them for sale; if they are good spawners, then-assuming, as there is reasonable ground for doing, that the spawn under favourable conditions will produce young oysters - the dumpy oysters, which remain on the grounds to a greater age than the normally grown ones, form a fairly stable spawning stock, for supplying spat in the future. In this case it is strongly advisable to keep on the grounds as many as possible of the dumpy forms.

\section{Comparison of the Characters of Normal, Dumpy, and Slightly Dumpy Oysters.}

The difference between dumpy and normally grown oysters is shown in the diagrams drawn to scale and given in text Figs. 1 and 2. The characters of the shells of dumpy oysters are as follows :-

(1) In outline a dumpy shell is roughly rhomboidal or of an elongated lozenge shape, while that of a normal shell is roughly circular.

(2) The shell is narrow, the antero-posterior axis (length) being constantly shorter than the ventro-dorsal (height). In a sample of 100 shells measured the relations length to height to width were $50: 59: 19$ respectively. In normal oysters the ratio, length to height, is 1 to 1 , or rather more than 1 to 1 , whereas in the sample of dumps cited the ratio is 1 to $1 \cdot 18$.

(3) The shells are relatively very wide, i.e. the distance between the middle of one valve and the middle of the other-across the mantle space --is relatively great; in samples of dumpy and normal shells of about the same shell area, the width of the dumpy to the normal will be of the order of 2 to 1 .

(4) The lines of growth on dumpy shells are very close together and numerous (see Bell, 2, Plate XII, Fig. 3), and although no definite experimental observation is available, it seems obvious that shell-growth occurs in most of these forms very slowly for the following reasons :-

(a) Their abundance on the grounds from year to year, even when there are only low stocks of "brood" to contribute towards an increase of dumps, and when over-fishing is occurring.

(b) The new growth at the end of the growing season-judged purely arbitrarily, but by practical experience of the difference between new and old shell in appearance, texture and super-added marine growths or their absence-is apparently very small and of the order of a mean increase in length at the median ventral edge of 6 to $8 \mathrm{~mm}$. (See Fig. 2.) 
(5) The umbo of the shell projects dorsally to the hinge so as to form a pronounced beak, and is especially well marked in the lower (left) valve. In normal forms the beak is very slightly developed.

(6) The space in the tightly closed shell (shell-volume) is much greater in relation to the size of the shell (shell-area) than in normally grown oysters. This is really a definite way of expressing the fact that dumpy shells are wider than normal ones; the width of a shell being very difficult

Fig. 1.

\section{B C}
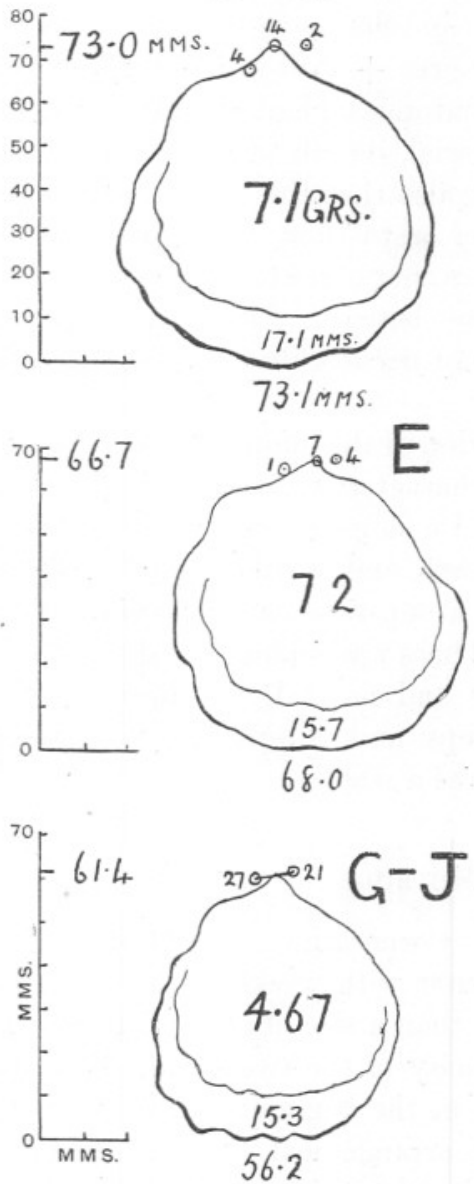
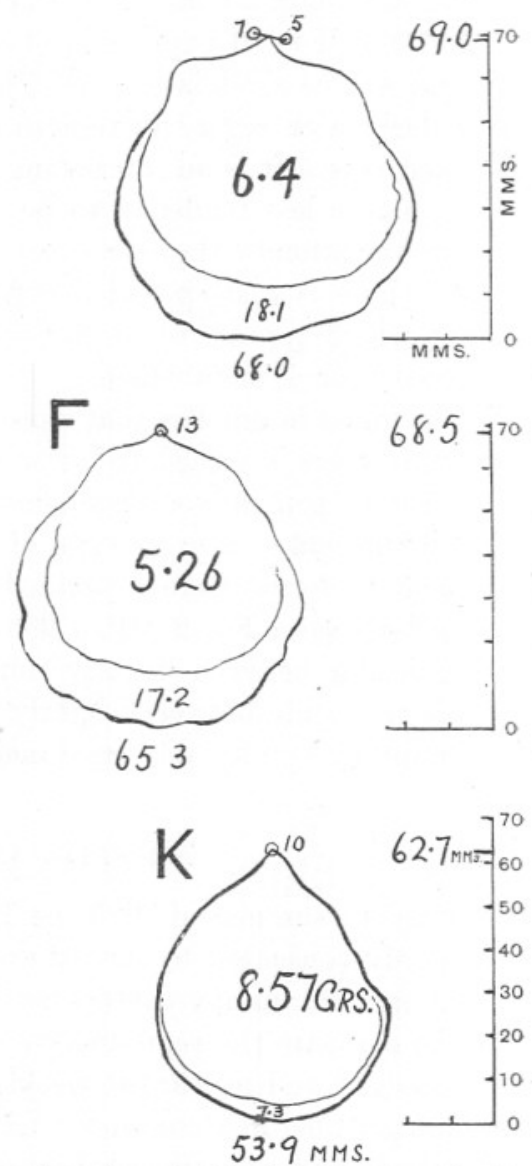

FIG. 1.-Diagrams of groups of well-grown oysters (except K) of similar size, showing average shape and size (length by height) plotted to scale, and correlated average weight of fish in grams and approximate average increment of shell-growth in 1925. (Turnaware Bar, Fal Estuary, Nov. 17, 1925.)

$\mathrm{B}$ and $\mathrm{C}, 20$ large normals; $\mathrm{D}, 12$ medium normals;

$\mathrm{E}, \quad 12$ medium normals; F, 13 medium normals;

G.H.I.J. 47 small normals; K, 10 good biconvex dumps. 
to define in figures. For example, 11 Mylor Bank dumps (2.12.25) with an average length by height 60.0 by $70.02 \mathrm{~mm}$., had an average shellspace capacity of $15 \cdot 27$ c.c., while 8 Mylor Bank normal (2.12.25) had the corresponding figures of $76 \cdot 4 \times 72 \cdot 1 \mathrm{~mm}$. and $11 \cdot 27$ c.c. average capacity.

(7) The shell ralves of dumps, especially the lower (left one), tend to be chambered, and are on the average attacked more by Polydora and Cliona ; a fact which may merely mean that the shells are older than those of the average normal ones existing on the beds.

There are differences also in the flesh of the dumpy oysters as compared - with normal ones; (a) the weight of the fish is not only greater than that of equal sized normal ones, but is greater in relation to shell-space, which we have noted is an expression of shell-area + shell-width. (Details of the work will be given later.) (b) The anatomical characters are different particularly with regard to reserve material, details of which cannot be discussed here. It is an interesting fact also that the "fish" of dumpy oysters shows less tendency to be green or to show greenness-due to copper absorption by the leucocytes - than that of normal oysters.

Thus there is a deep-seated difference between dumpy and normal oysters, which appears to be, but may not necessarily be, due to a mere difference in shell metabolism.

It was found in practice that a proportion of the dumpy oysters showed some characters intermediate between characteristic dumpy and normal forms, having generally a longer shell and a shape nearer the normal, and being intermediate also in type of growth and width of shell. These intermediate forms were examined in a separate category and called slightly dumpy (see Fig. 2, OP, p. 203). There was seldom any difficulty in distinguishing between slightly dumpy and normal, but it was often difficult to decide between slightly dumpy and dumpy, for this reason the dumpy oysters are discussed mainly as a whole.

\section{Material and Methods.}

During the summer of 1925 the Truro Corporation (River Committee) courteously consented to supply the writer with weekly samples of 100 normal and 100 dumpy oysters not less than a size of about 2 inches, in order to compare the reproductive capacity of the two kinds. Samples were dredged and forwarded weekly from the beginning of July to the end of September in accordance with this arrangement. At the beginning of the dredging season (in October) samples of oysters were bought (for the Marine Biological Association) directly from the dredgermen by the writer and afterwards samples were again sent on by rail. Normal and dumpy oysters were taken in the same hauls of the dredge or-when the sample of normal was taken before the total of dumpy required was collected-by 
row-boat dredging over the same ground or sail-boat dredging over the same ground until about 100 dumps were collected.

The results of the examination of the samples are shown in Table I on page 205. The samples were examined on the day of arriral and the recording completed mostly during the following day. Sick oysters were isolated at once in dishes as soon as found, and examined first: most of the sick oysters could be detected at or soon after the opening of the box in which they were consigned. In all samples except

Fig. 2.

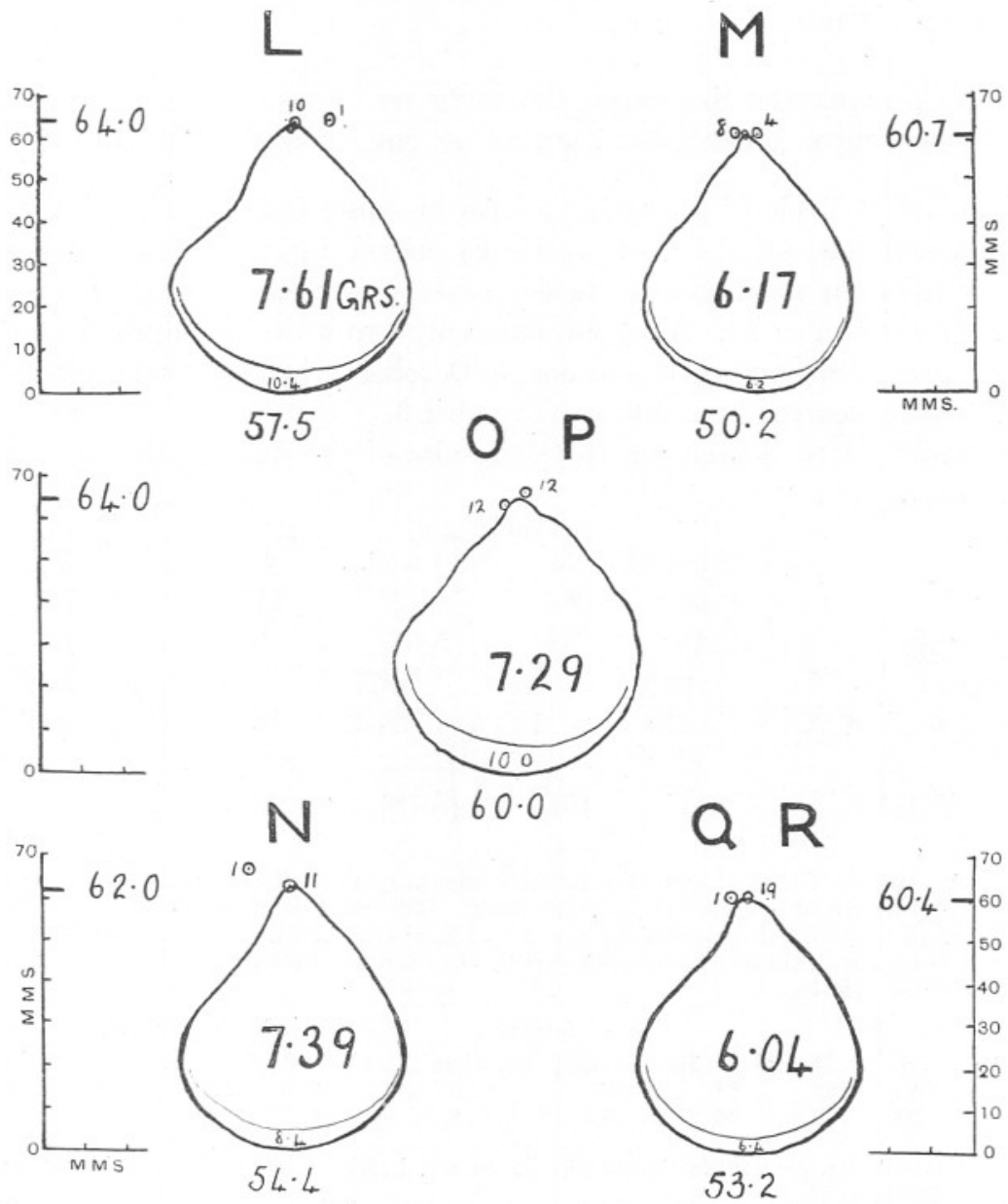

$\mathrm{FI}_{\mathrm{G} .}$ 2.-Diagrams of groups of dumpy and slightly dumpy oysters of similar size, showing average shape and size (length by height) plotted to scale, and correlated average fish-weight in grams, and approximate average increment in shell-growth in 1925. (Turnaware Bar, Fal Estuary, Nov. 17, 1925.) L, 12 dumps; M, 12 smaller dumps; N, 12 slightly dumpy approaching dumpy ; $O$ and $\mathrm{P}, 24$ larger slightly dumpy; $Q$ and $R, 20$ smaller dumpy. 
a few, macroscopic and microscopic examination was used to find the pure ripe females, as well as those spawning. Later it was found possible to pick out the ripe females by eye and low power lens examination only with, however, an occasional error ; some pure males and most hermaphrodite forms have the same opaque chalky appearance as the body of the ripe females, but in the case of the males a slight cut in the body is sufficient to disclose the clumps of ripe spermatozoa to an eye behind a low-power lens. For the purpose of this paper it will be sufficient to notice here briefly only the ripe and ripening females along with the spawning females.

\section{The Comparative Spawning Capacity of Normal and Dumpy Oysters from a General Review of the Observations made.}

A glance at Table $I^{*}$ will show that the breeding had begun in the first sample examined (July 1) and practically ceased during September; the last occasion on which two white-sick oysters were found in one sample being on September 16. After this date only two white-sick oysters were taken, one on September 30 and one on October 8, but occasional blacksick oysters occurred to as late as November 3 .

From July 1 to September 16 the results of the examination of the three types are :-

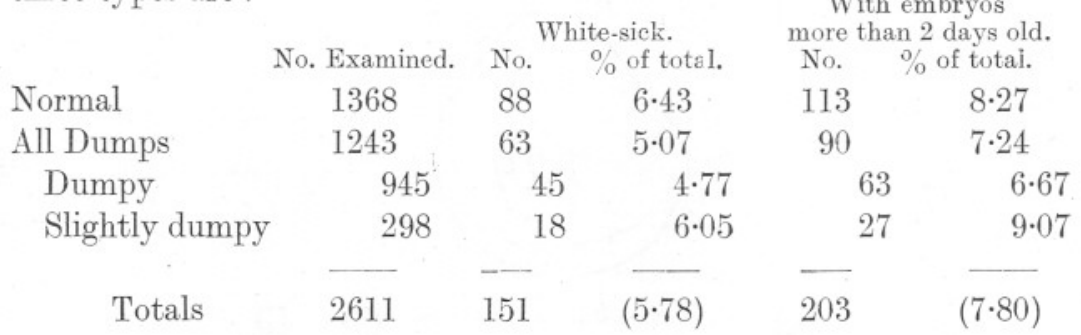

* The samples of normal oysters included a large proportion of small, that is less than $2 \frac{1}{2}$ inches in length or height, but also some large. The samples of dumpy oysters were mostly small with a small proportion round about legal size, i.e $2 \frac{1}{2}$. inches. All the earlier samples and many of the others were measured; the results of the examination of samples. 1 and 4 are as follows:-
No.
No, of normal.
No. of dumpy.

$\begin{array}{lcrcccccc} & \mathrm{N} & \mathrm{D} & \text { above } 2 \frac{5}{8} & \text { above } 2 \frac{1}{2} & \text { less than } 2 \frac{1}{2} & \text { above } 2 \frac{5}{3} & \text { above } 2 \frac{1}{2} \text { less than } 2 \frac{1}{2} \\ \text { July 1 } & 84 & 89 & 21 & 37 & 26 & 8 & 17 & 64 \\ \text { July 22 } & 94 & 106 & 31 & 55 & 8 & 19 & 25 & 62\end{array}$

The average new growth (estimated as increase in height) July 1 normal=10 $\mathrm{mm}$.; dumpy $=7 \cdot 0 \mathrm{~mm}$.

The average new growth July 22 normal $=11 \cdot 1 \mathrm{~mm}$.; dumpy $=5 \cdot 7 \mathrm{~mm}$.

Note. Among a small number of individuals, a few dumps with a big shoot of say 10 to. $15 \mathrm{~mm}$ will increase the average to a relatively high figure. The age of the normal oysters: may be estimated to be mainly 4 to 5 years, but ranging from 3 to 7 or 8 . The age of the: dumps is not determinable, but is probably on the average 2 to 3 years higher.

The years new growth is shown representatively in Figs. 1 and 2, pp. 201 and 203. 


\section{TABLe I.}

Results of the examination ${ }^{1}$ of weekly samples of approximately 100 normally grown and 100 dumpy oysters for spawning individuals and pure ripe females (normal only) from the Truro oyster beds, Fal Estuary, during 1925. (Including one sample on August 11 from the Falmouth North Bank, north of the Cross Road Channel.)

$\mathrm{N}$. =normal ; Sl. D.=slightly dumpy ; D.=dumpy. I=Stage I, or with embryos to about two days old ; II =Stage II, with larvæ mainly shelled or more than two days old.

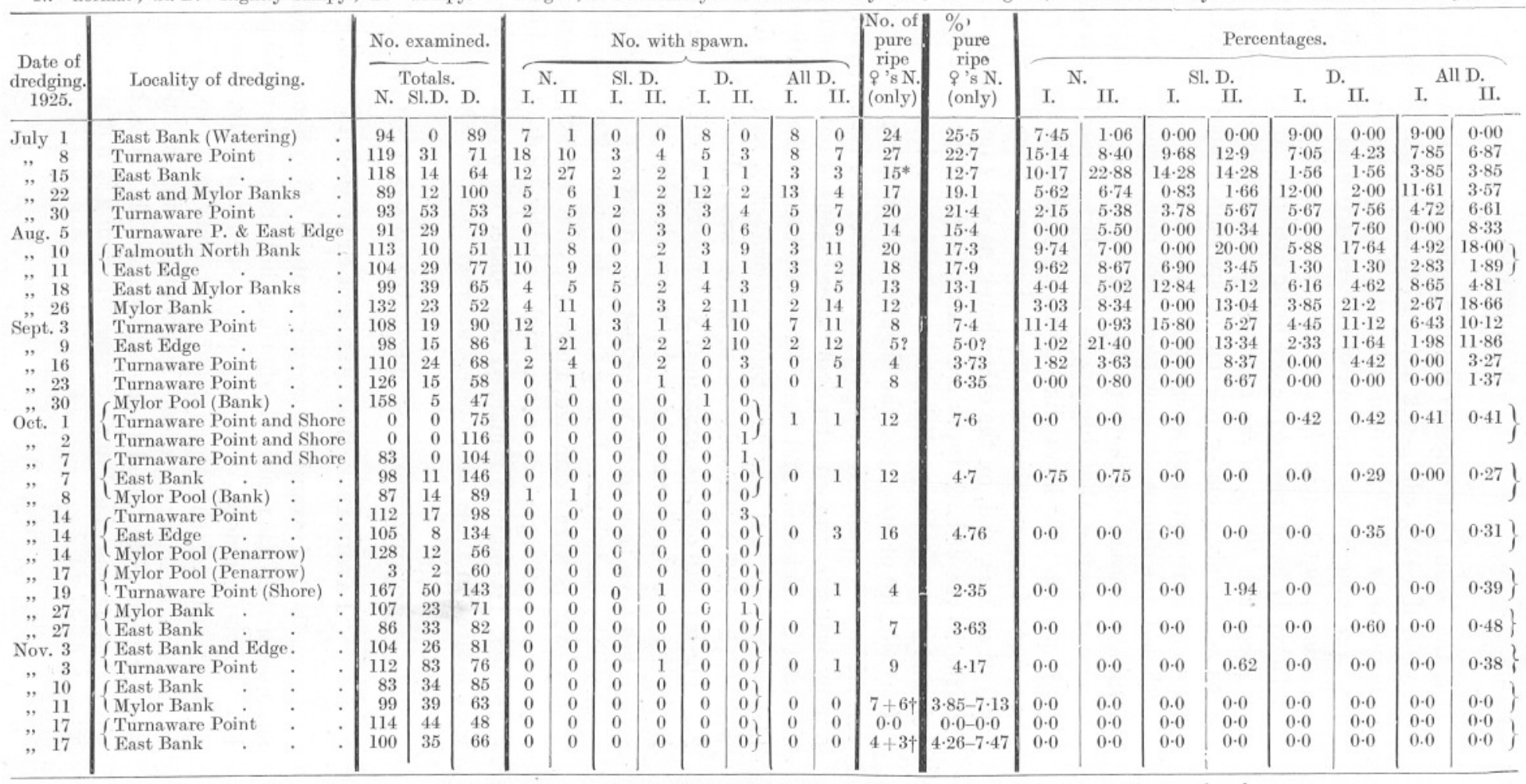

* Number calculated, as all the oysters in the sample could not be examined microscopically. † Ripening females.

${ }^{1}$ See the footnote on the bottom of page 204 for further details of the characters of the samples. 
It is thus seen that whereas the normally grown oysters on the whole total yielded $6.43 \%$ white-sick and $8.27 \%$ black-sick, on the whole total of dumps only $5 \cdot 07 \%$ white-sick and $7 \cdot 24 \%$ black-sick were taken. These percentages are not those of oysters spawning out of the total on the grounds, but merely those of the oysters examined, some of which would already have spawned before being dredged. It will be shown later that more than $100 \%$ of the normals spawned during 1925 , and as the dumps were only slightly inferior in spawning capacity nearly every dump must have spawned at least once also in 1925 .

Although the dumps are now seen to be not so good as the others for spawning purposes, yet they are only slightly inferior. There can remain no doubt, therefore, that dumps are valuable for breeding inasmuch as a high proportion yield larvae like normal individuals. We have no means at present of ascertaining the survival values of the larvae of the two types of oysters, and, on the other hand, no substantial reason to doubt that the larvae of both types are healthy and will produce spat equally well under favourable conditions.

It is worthy of note that the slightly dumpy group are more like the normal in their spawning capacity, and that of the 1922 normal and 2149 dumpy oysters examined after September 16 the normal gave only 1 whitesick and 2 black-sick, and none after October 8 ; the slightly dumpy 3 black-sick only, but one as late as November 3, and the dumpy one white-sick and 3 black-sick, one of which was taken as late as October 27. The last 810 oysters, examined November 10 and 17, gave no spawning oysters, so that it may fairly be stated that the end of the spawning season has been thoroughly investigated. Reference to this part of the work will be made later. During the whole season 3290 normal and 3392 dumpy oysters were examined, making a total of 6682 , nevertheless, the number is not regarded as too high for the kind of problem being examined. It may be remarked that other characters than spawning were noticed in these later oysters in order to avoid wastage of material.

\section{PERIODICITY IN THE SPAWNING HABITS.}

\section{Favourable Weather for Spawning in 1925.}

The method of examining weekly samples of oysters throughout the summer of 1925 has resulted in showing that among the whole population, but especially among oysters growing shell normally, there is an undoubted, although slightly irregular, periodicity in the spawning, and that the maximum spawning occurs at about the time of full moon. This is well shown in Figs. 3 and 4, pages 210 and 211. It is, however, equally clear that among the dumpy oysters spawning is not so regular. (See Figs. 5, 6 and 7.) 
As is well known the summer of 1925 was more than normally warm and therefore favourable for the spawning of oysters. It will probably be many years before such a favourable summer will occur again ; and since the temperature remained high enough over at least most of the summer to permit oysters to spawn at such times as they were ready, an opportunity occurred of observing whether there exists any tendency for rhythmical breeding in this mollusc. No one has previously demonstrated rhythmical breeding in the oyster, although the ancient naturalists, as Philpots (3) and recently Fox (4) have shown, stated that oysters were fat at full moon and "empty" at new moon, while Tarentines are stated to hold the same belief at the present day. (See also page 221.)

\section{Description of the Truro Oyster Beds and Discussion regarding the Biological Similarity of the Population examined.}

The main Truro oyster beds of the Fal Estuary lie between the Falmouth Harbour proper and the Fal River, in a lake, or widening of the Estuary, in which the main channel, 14 to 9 fathoms deep, crosses the lake diagonally, while shallow banks occur on the south-west to west, and east to north-east sides of the channel. (See 5.) There is an eddy tide on both sides of the main channel. The general hydrographical conditions of the lake are not known, but from the general similarity of the East and West Banks, it is believed that such hydrographical and biological differences as may occur in the waters over the two banks would not be significantly different on the whole in their influence on the spawning habits of the oysters. There is, however, reason to believe that oysters in the Channel itself might be significantly different from those on the adjacent banks, and some samples were obtained from the East Edge, a locality where the East Bank slopes at a depth of 2 to $2 \frac{1}{2}$ fathoms towards the Channel proper. The localities from which samples were taken are :-

(1) East Bank, with depths of about 0 to $1 \frac{1}{2}$ fathoms at low water.

(2) East Edge, at depths of $1 \frac{1}{2}$ to $2 \frac{1}{2}$ fathoms shelving towards the Channel.

(3) Mylor Bank and Pool, similar to the East Bank, but on the west and south-west side of the Channel.

(4) Turnaware Point and Bar, the northerly continuation of the East Bank which juts out to form a bar, and is partially exposed at low spring tides.

It was found in practice difficult to obtain all the material from one place, as efficiency in dredging varies with exposure to different strong winds. Ideal material would, however, be obtained from the same place, 
but periodicity in breeding was not contemplated when the research was begun.

One sample of oysters was especially obtained from the Falmouth North Bank (in the grounds under the administration of and supplied by the courtesy of the Falmouth Corporation [Harbour Committee]) for the critical second week in August. That Bank is a continuation of Mylor Bank, but runs off towards the Cross Road Channel in slightly deeper water. It may be expected that in its nearer position to the open sea, the Falmouth North Bank would have a slightly higher mean salinity with correlated hydrographical variations than situations higher up on the Mylor Bank, and as the nature of the bottom is harder there would occur also a biological difference, but whether these differences would be significant in their effect on spawning cannot be stated. It was actually found that the normal oysters taken from the ground were remarkably similar to those taken at the same time from the East Edge, but that there was an astonishing difference in the dumpy oysters from the same two localities. It would appear, therefore, that the normals had spawned similarly at about full moon in these two localities, but that whereas the dumps from the waters of the Falmouth Bank also spawned at the same time as the normals, those on the East Edge did not.

With regard to the Truro samples, the critical ones taken about full moon on July 8 and September 3 were from off Turnaware Point, and that of August 5 mainly from the same locality; while of those taken in the weeks after full moon, the sample taken on July 15 was from the East Bank, and those of August 11 and September 9 were from the East Edge. Thus, the corresponding samples at the critical periods of full moon and the week after are either from the same place or a locality very near.

On the whole there is little reason to believe that the oysters on the grounds sampled did not form a fairly homogeneous population with regard to general biological environment; on this basis, therefore, and until the contrary can be shown, the weekly samples may be taken to be representative of an approximately uniform population.

If, on the other hand, a different point of view be taken, and the results obtained be considered, then the orderly rhythmical breeding period shown by the normal oysters in two out of the three months - and the variation in the middle month of August, apparently due to the sudden cold spell of weather at that time, is really also confirmatory of what we know of the oyster in relation to temperature change - may be regarded as confirming the view-but not proving - that the samples were representative of an approximately homogeneous population with regard to spawning behaviour. If, however, it is a fact that normal oysters everywhere spawn chiefly at full moon, proof will soon be forthcoming in the future from populations undoubtedly dissimilar in other respects. 


\section{The Spawning of the Normal Oysters.}

The results of the examination of the samples may now be discussed as shown in the graphs in Figs. 3 to 7 . In Fig. 3, page 210, are shown the total percentages of normal oysters spawning each week throughout the summer (thick line). In the months of July, August and September the peaks of the graphs occur in the week after full moon, at which time those oysters which spawned in the full moon period will have embryos mainly a week old, but more than two days old. If oysters spawn during say five days of the full moon period a smaller percentage in spawn may be expected in a sample taken at or in the days preceding full moon than later, but, since oysters retain their embryos for certainly a week, a sample taken a week after full moon will contain all those oysters which spawned round about the period of full moon, and the percentage will be a maximum, or higher than in samples taken a week earlier. There can be no doubt that this is the explanation of the occurrence of the peaks of the graphs in the week after full moon. It is worthy of note that there is also a small peak in the week after the full moon in October. Thus Fig. 3 seems to show that there is clearly a regular periodicity in the breeding of the oysters and that a maximum of spawning occurs round about the days of full moon. The writer has shown elsewhere (6), however, that white-sick oysters, i.e. oysters with very young embryos, must be interpreted with care, that they may in fact be forced spawners. A long experience in inspecting recently dredged oysters and examining the state of development of the embryos carried by such, leaves no doubt that the mere disturbance due to dredging or lying about in the sun, or being crowded in a bag out of water, may cause individuals to spawn prematurely, if such are ripe, or even nearly ripe. For this reason the percentages carrying embryos up to about two days old (about the stage of the ciliated trochosphere) and those carrying embryos more than two days old (shelled larvæ) are shown separately in Figs. 4 and 5. In Fig. 4, p. 211, which shows the normal oysters with embryos, there is seen to be a high percentage of recently spawned oysters at full moon in July and September, but the highest percentage in August falls in the week after full moon; on the other hand, the highest percentage of oysters with embryos two days to a week old falls in the week after the full moon in July and September, but in August there are two peaks, one after the full and one after the new moon period. Further, in July and September the percentage of oysters with recently extruded embryos falls off rapidly from full moon and fairly rapidly also in August from the week after full moon. Similarly the percentage of oysters with old embryos falls off rapidly in July and September at a similar rate to that of oysters with young embryos; in August, however, there are 
Fig. 3.

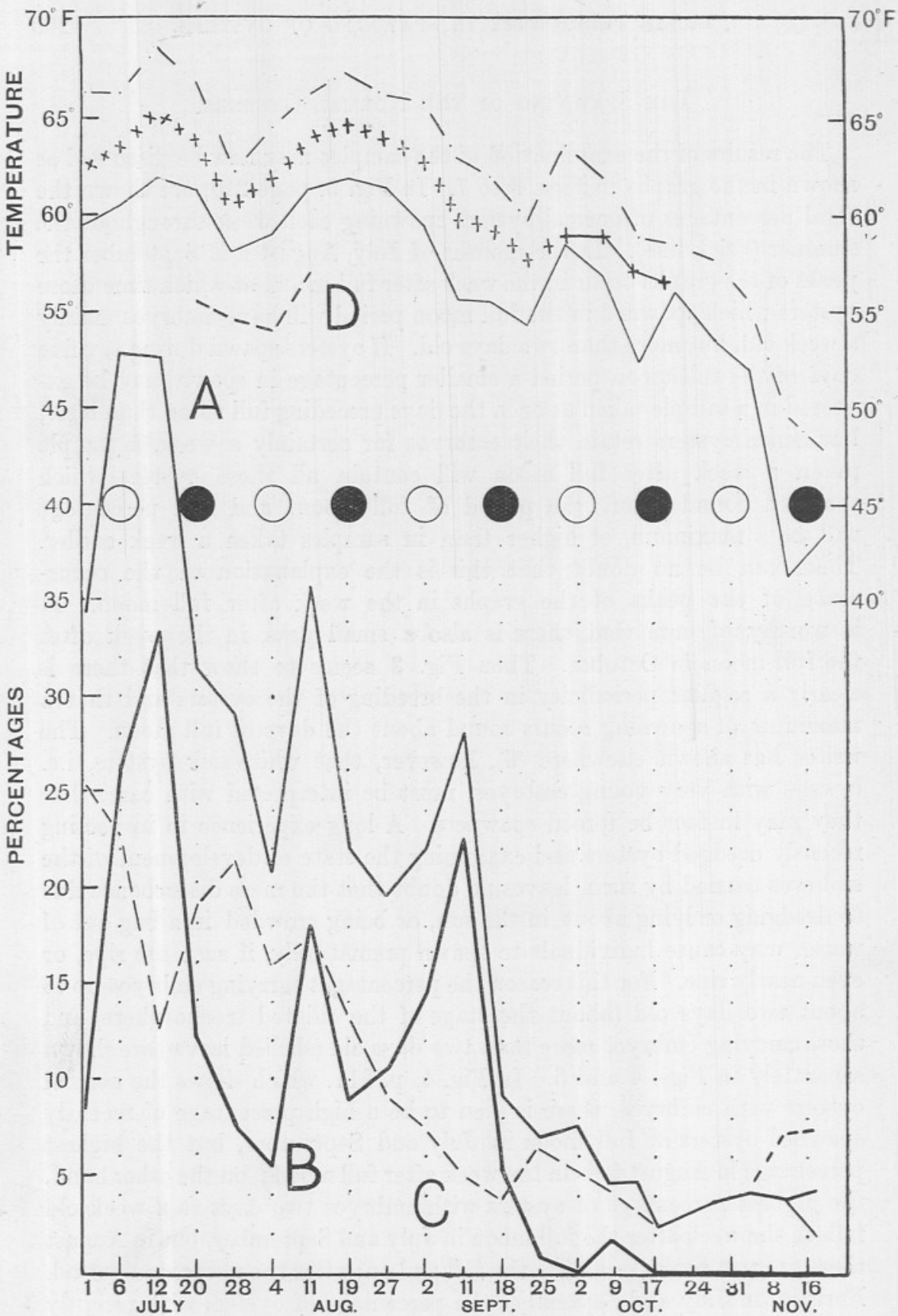

FIG. 3,-Graphs showing the weekly percentages of

(A) total female oysters $(B+C)$, (B) total spawning oysters, (C) total pure ripe but unspawned females in relation to the moon's phases among oysters with normally grown shells frcm the Truro beds. Fal Estuary, 1925 (age estimated at mainly 4 to 5 years, but extending probably from 3 to 7 or 8 ).

The thick broken line branching from the graph A at the end of October shows the increasing percentage of recognisable ripening females. The graphs at the top of the figure show mean maximum (dots and dashes) and mean air temperature (continuous line) at Falmouth, with the approximate mean sea-temperature over the oyster beds indicated by crosses.

At $\mathrm{D}$ are given the mean minimum air temperatures round the period of the August full moon. 
again two peaks, but with a minimum value towards the September full moon. The analysis given in Fig. 4 confirms the result shown in Fig. 3, but points to a disturbance of the indicated rhythm by something occurring at the beginning of August. It is an interesting fact that at full moon and round about the period of full moon spring tides in August there occurred a cold spell of weather (see Fig. 3 D.) while on August 5 (at full moon) a minimum temperature of $51 \cdot 2^{\circ} \mathrm{F}$. and a rainfall of $31 \mathrm{~mm}$. was recorded at

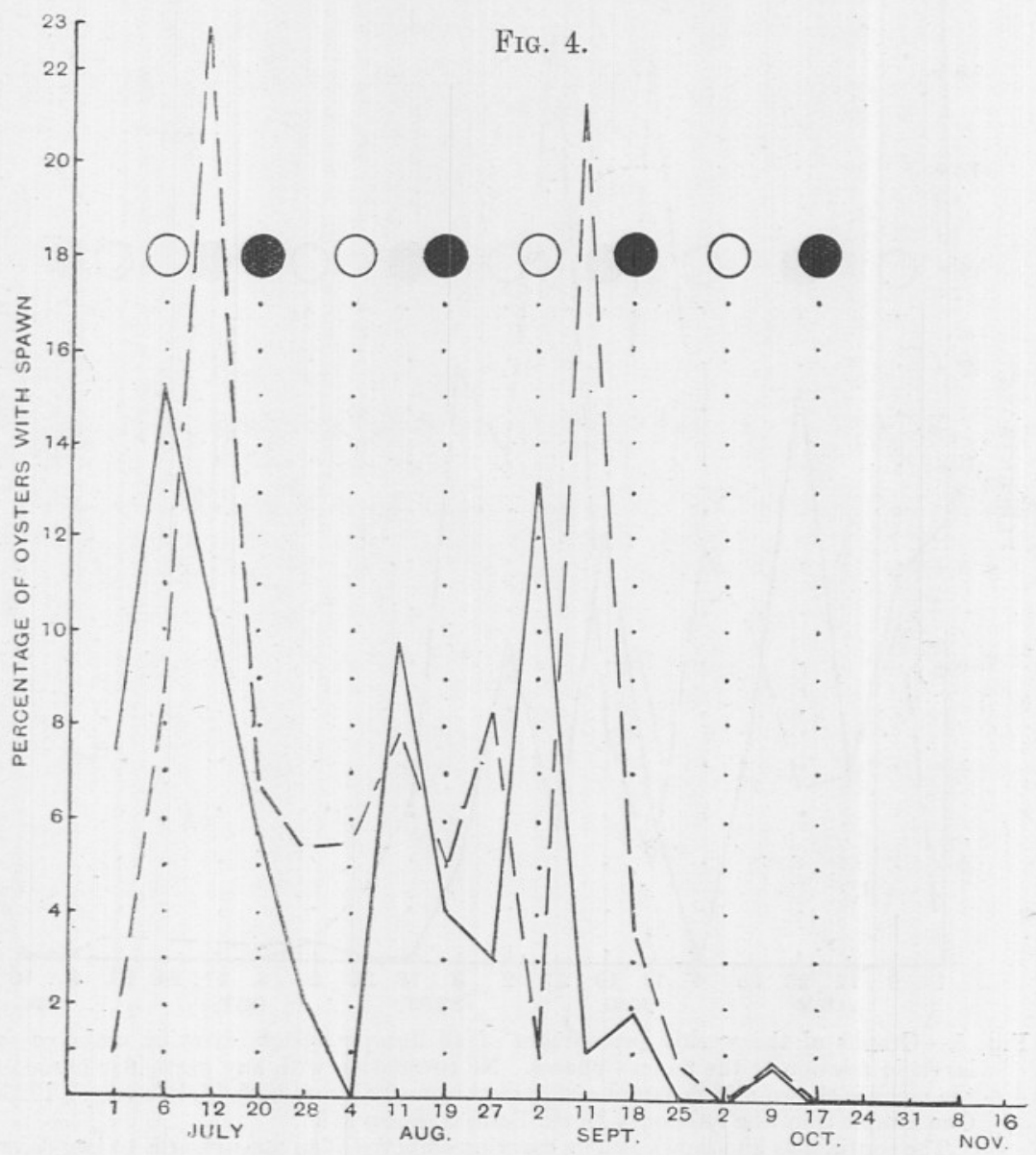

FiG. 4.-Graphs showing the weekly percentages of oysters carrying embryos or larvæ in relation to the moon's phases, indicating an irregular correlation between lunar periodicity and breeding phenomena; from samples of oysters with well-grown shells from the Truro oyster beds (Fal Estuary), 1925.

The continuous line shows oysters carrying embryos of an age upwards to about two days.

The broken line shows oysters carrying embryos mainly fully shelled or older than about two days.

Full moons are shown by the circles, and new moons by the filled-in circles, here and in Figs. 5, 6, and 7. 
Falmouth. (See 7a and b, Monthly and Weekly Weather reports of the Meteorological Office.) Unfortunately there are no sea-temperature records available for the Falmouth oyster beds, or the sea near the oyster beds, to correlate with the spawning conditions observed from July to October, 1925, but the mean maximum air and mean air for Falmouth (" 7 a) is shown

Fig. 5.

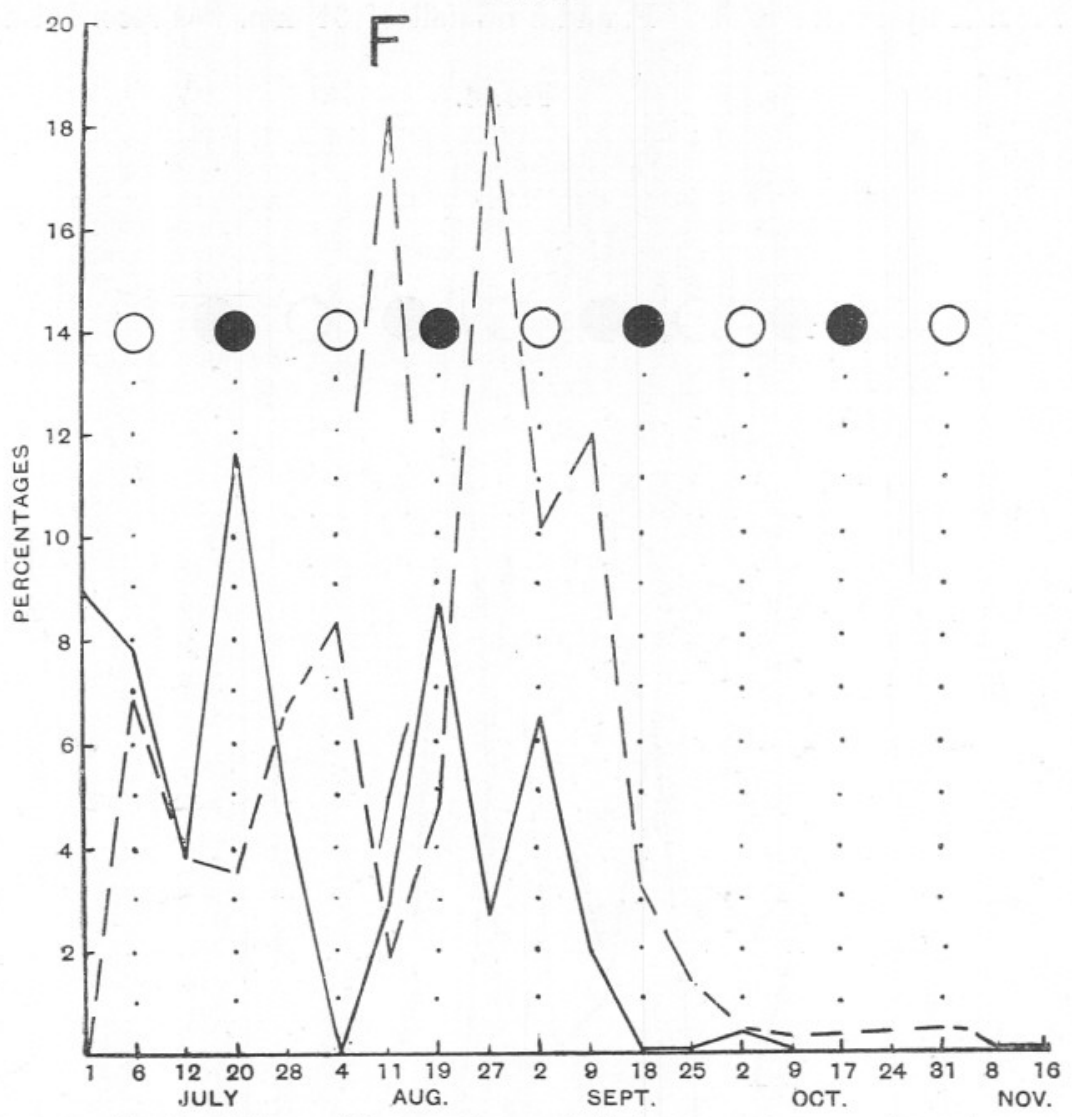

FIG. 5.-Graphs of the weekly percentages of all dumpy oysters carrying embryos or larvæ in relation to the moon's phases. No correlation with any particular phase of the moon is shown : from samples of oysters from the Truro beds (Fal Estuary), 1925. One sample from the Falmouth North Bank is shown at F.

The continuous line shows oysters carrying embryos of an age upwards to two days.

The broken line shows oysters carrying embryos mainly fully shelled or older than about two days.

in Fig. 3 along with a few sea observations made on the beds by the writer in October. From this information it is possible to obtain an approximate indication of the sea-temperature over the oyster beds, for the writer has shown (8), and in unpublished work, that whereas in the deeper water at the mouth of the Thames Estuary mean sea follows mean air- 
temperature almost exactly but with a lag period of a fortnight, at situations higher up the estuary in shallower water mean sea-temperature rises above mean air with a decreasing amount of lag, and on the oyster beds in 1 to 2 fathoms:-

(1) From April to September mean sea-temperature may be from 2 to $5^{\circ} \mathrm{F}$. above mean air, whether the preceding period has been warm as in 1921 , or somewhat cold as in 1922 .

(2) Mean sea-temperature remains above mean air-temperature for the greater part of the year; fluctuation in the relative values of sea- and air-means may occur in the winter months.

(3) Low-water means are higher than high-water means from about May to September, and lower or about the same from November to March.

(4) Sea-temperature monthly means vary directly with air-temperature means without any lag.

The temperature variation over the Truro oyster beds may be predicted to be somewhat similar to those occurring over the Whitstable beds, but attaining neither the higher nor the lower values of that region, because of the influence of the Channel water. Therefore, with regard to the lowwater temperature in the August tides on the Truro beds, although the temperature might be reduced to a very low figure, especially at midnight at full moon on August 5, it is not possible to estimate a probable figure in view of the absence of temperature readings from the grounds at some date near that period. It is certain, however, that during the August full moon tides there would be a sensible drop in the water-temperature, especially at low water. This conclusion is of great interest in connexion with the detection of the direct stimulus which produces spawning, namely, that there occurred a sudden drop in the temperature at the time a general spawning was due, which was followed by an irregular spawning in the month of August, with, however-

(1) a maximum of recently spawned normal oysters in the week after full moon (see Fig. 4) apparently delayed one week.

(2) two maxima for oysters with embryos about a week old in the week after full and new moon, that is after the spring tides.

The occurrence of an abundant spawning in the full moon period of September following the irregular month of August is of special interest in connexion with the problem of the proportion of the whole population spawning in one season, and with the probability that while one section of the population is spawning another proportion is ripening. 


\section{The Spawning of the Dumpy Oysters.}

Before discussing further the causes of the irregular periodicity observed in the spawning of the normal oysters, it is necessary to consider the spawning behaviour of the dumpy oysters, which is shown in Figs. 5, 6, and 7. Fig. 5, p. 212, shows the weekly percentages with embryos two days old, and those with embryos more than two days to about a week old, Fig. 6 compares the percentages of normals and dumps with the older

Fig. 6.

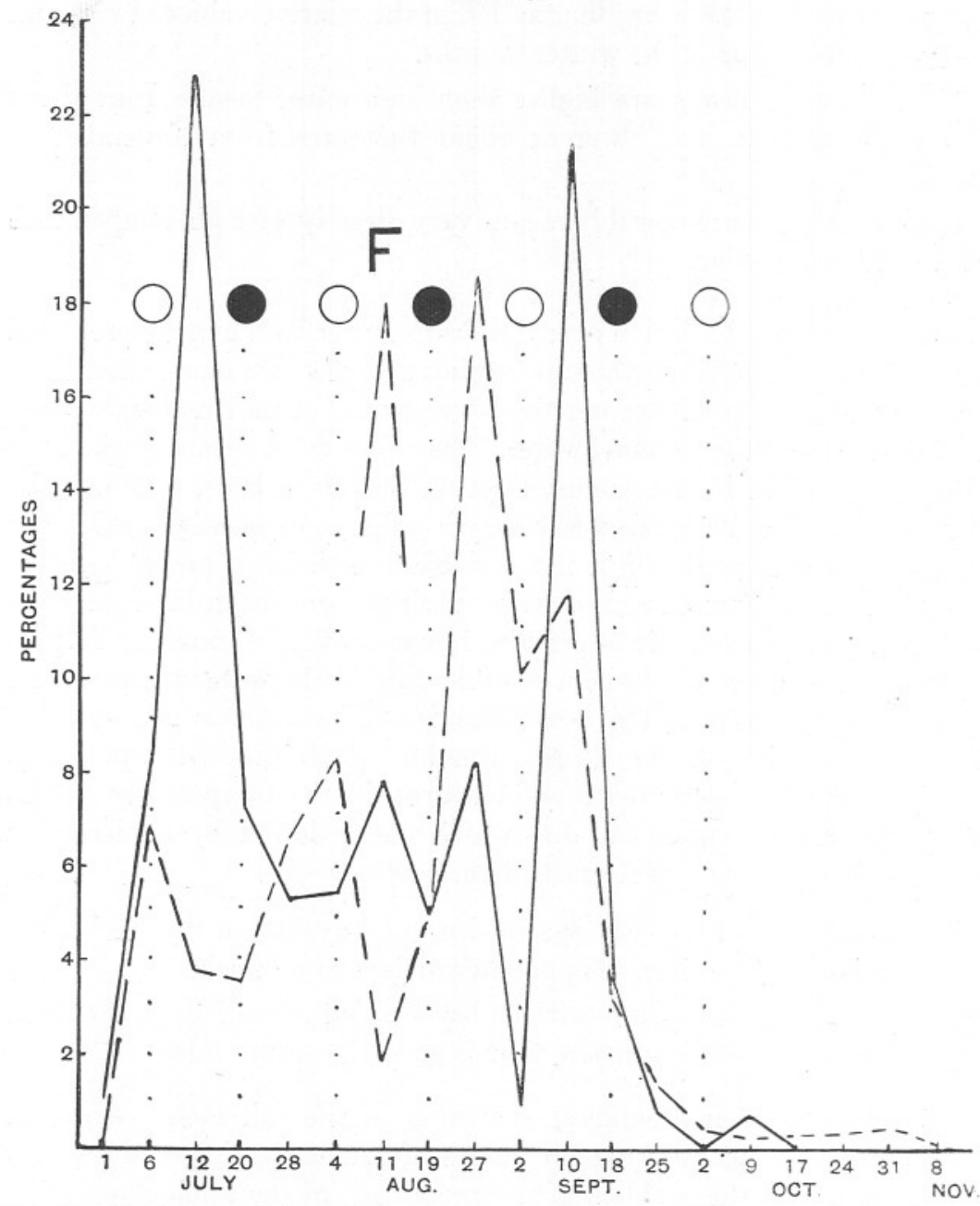

Fig 6 -Graphs comparing weekly percentages of normal (continuous line) and dumpy oysters (broken line) carrying embryos mainly fully shelled or more than about two days old ; from the Truro beds (Fal Estuary), 19:5. One sample from the Falmouth North Bank is shown at F. 
embryos, and Fig. 7 compares the total in spawn of both normal and dumps. In Figs. 5 and 6 the results of the examination of the dumps from the Falmouth North Bank are also shown at F. A glance at Fig. 5, p. 212 , shows that the spawning of the dumps is entirely irregular as compared with the normals. The graph of percentage of oysters with young embryos (unbroken line) shows three peaks, two at new and one

Fig. 7.

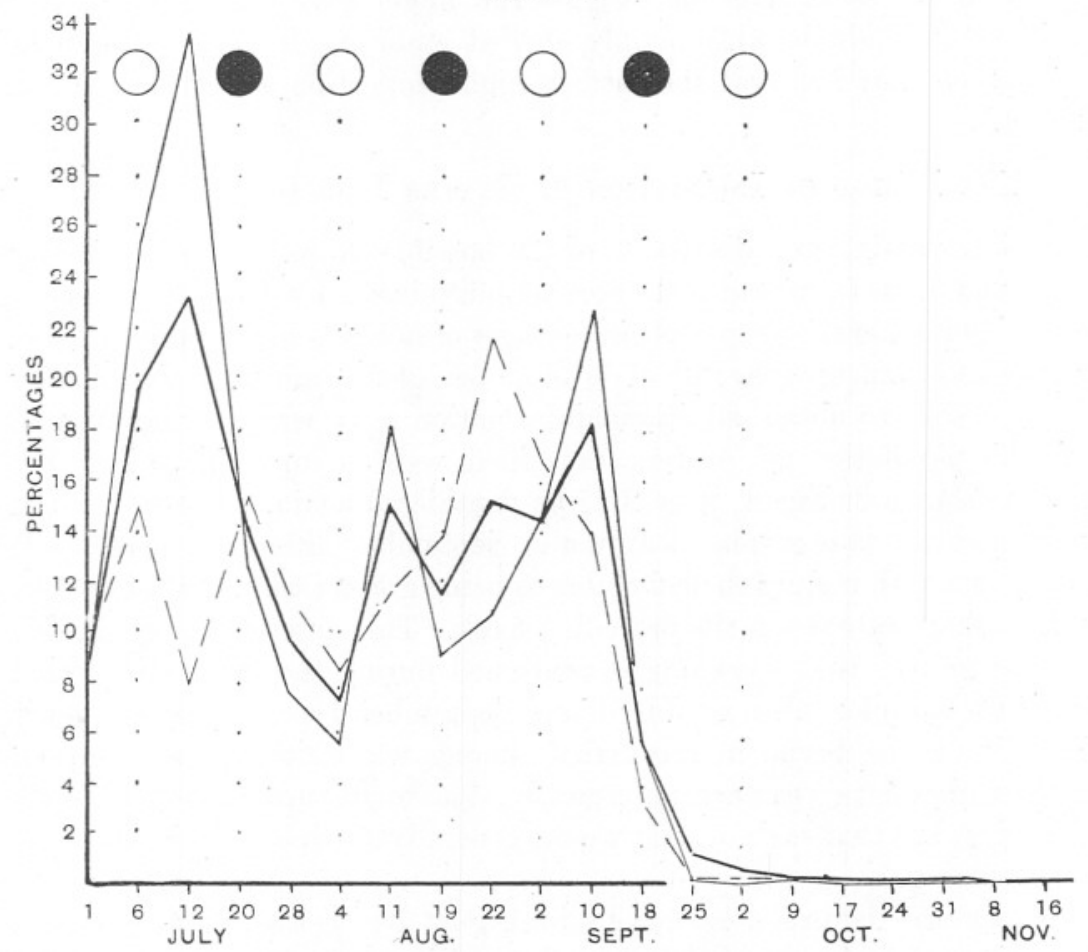

FIG. 7.-Graphs comparing the weekly percentages of all normal and all dumpy oysters spawning, and the percentage spawning in all samples of all kinds combined (Truro oyster beds, Fal Estuary, 1925).

The thick line shows percentages spawning of all samples of all kinds (including the sample from the Falmouth North Bank) combined, the thin line shows percentage of all normal spawning, the broken line the percentage of all dumpy spawning.

at full moon, while the graph of percentage with older embryos (broken line) shows peaks at full moon (twice), the week after full moon (twice), and one high peak after new moon, while from Fig. 7, broken line, in which the total percentage of dumps spawning is compared with the normal and the whole population, it is seen that of the three maxima, one is at full, one at new moon, and one the week after new moon. 
It is clear, therefore, that the spawning of the dumpy oysters is quite irregular, whether the total spawning be considered or the percentage spawning with advanced embryos at the time of examination. Thus, besides the abnormality of dumpy oysters in shell metabolism, it is seen that they are also abnormal in their spawning behaviour as compared with normal individuals. Although generally speaking the dumps are irregular in spawning, the sample of dumps from the Falmouth North Bank in the week after the August full moon gave the high figure of $18 \%$ of individuals with mainly shelled embryos, indicating that the dumps on that bed had spawned in high proportion about August full moon.

\section{The Period of Incubation of Oyster Larve in the Sea.}

Before passing to a discussion of the possible causes of the periodicity observed in the spawning of the normal individuals, it will be convenient to examine further the graphs of percentages of normals in spawn in relation to the known facts of the rate of development of the embryos. In this way it is possible to obtain additional information as to whether the samples of the population of oysters examined were comparable. Let the results shown in Fig. 4, page 211, be considered again. The maximum values of the two graphs in July and September differ, the percentage of oysters with mainly shelled embryos being greater than that of oysters with young embryos in the preceding week. This difference is explicable on the ground that spawning is continued during the full moon period after the samples taken on July 6 and September 2 were dredged, and it has also to be borne in mind that among white-sick oysters may be some which have spawned unnaturally, due to disturbance on or after dredging, but that such oysters would generally be ripe ones on the point of spawning.

If now the disturbed conditions in August be ignored, it will be seen that the graph of oysters with old embryos follows significantly closely the graph of oysters with young embryos with a lag period of one to about one and a half weeks. From this it may be inferred, if the members of the population are approximately similar, that oyster embryos develop to the shelled stage and are expelled by the parent in a period of one to one and a half weeks. As it can be shown that the larvæ do develop to the shelled stage in about a week at summer temperatures, there is, therefore, an additional reason for the assumption that the population of oysters examined was in fact approximately uniform in spawning capacity. It is a difficult matter to obtain the actual age of the embryos of oysters, as the beginning of spawning can only be rarely observed, but the age can be obtained approximately by noting the approximate age, to within 12 to 24 hours, of oysters with young spawn and observing the subsequent rate 
of development, as in the following experiments carried out by the writer.

July $29,1920$.

(1) Segmentation stages (age ca. 24 hrs.)
Trochosphere stages (age ca. 48 hrs.)

(age ca. 48 hrs.)
Aug. 3, 1920.

Embryos shelled and black

Aug. 4, 1920.

Embryos shelled and black ditto and black
Age. Temperature. ca. 6 days $\quad 59 \cdot 2^{\circ}$ to $65 \cdot 5^{\circ} \mathrm{F}$. mainly $63^{\circ}$ to $64^{\circ}$

Temperature. $59 \cdot 2^{\circ}$ to $65 \cdot 5^{\circ} \mathrm{F}$. mainly $62 \cdot 5^{\circ}$ to $64 \cdot 0^{\circ}$ ditto mainly $62 \cdot 5^{\circ}$ to $64 \cdot 0^{\circ}$

In these cases the embryos were taken from the parent and placed in shallow dishes in a tank in the Plymouth laboratory.

Spärck records a similar case (9, p. 31) of an oyster with eggs in segmentation stages (up to $24 \mathrm{hrs}$. old) 20 July, and swimming larvæ 25-26 July, in six to seven days, and two other similar cases (loc. cit. p. 46). We now know, therefore, from experiments, that oysters will usually reach the black-sick stage about one week after spawning. This result confirms the more important field observations of Mr. Louis French who, during a great many years experience as a practical oyster producer at West Mersea, Essex, has observed that black-sick oysters may be found on the beds generally about one week after white-sick ones are found, and that settled spat may be expected in warm weather ten days to a fortnight after the first black-sick oysters are seen. Generally, settled spat may be taken in fair numbers in normally warm weather about one month after the first batch of white-sick oysters is seen, as the writer has several times had the opportunity of verifying on the beds.

Apart from direct observations on successive batches of oysters taken from beds in the sea, it will be difficult to obtain reliable information on the normal period which oyster larvæ pass in the mantle cavity of the parent, but valuable observations on the matter may, however, be expected from the large scale tank experiments being carried out by the English Fisheries Department at Conway, where large numbers of oysters are probably allowed to remain undisturbed during the incubation of their young. If incubating oysters are disturbed they are liable to behave abnormally and throw out their young even in very early stages of development. There is need for far more extensive and precise information about oyster embryos and larvæ than exists at present. (See also Spärck 9, p. 46.)

We have seen, therefore, that if the normal oysters examined from the Falmouth grounds be assumed to be representatives of a similar population, then the period which oyster young pass in the mantle cavity of the parent is about one to one and a half weeks (at a temperature unknown) ; on the other hand, practical experience and experiments point to a period of one to two weeks as the period of incubation of oyster young, and 
thereby confirm the assumption that the Falmouth normal oysters were in fact an approximately uniform population with regard to spawning capacity and behaviour.

\section{Discussion on the Probable Causes of the Periodicity in the Spawning OF THE OYster.}

As it has now been shown that spawning in normal oysters is periodical and that a maximum of spawning certainly occurred about full moon on the Fal Estuary beds in 1925, while, on the other hand, it is clear that dumpy oysters spawn irregularly, it is possible to discuss the probable causes of the rhythmical character of the normal spawning. In order, however, to explain satisfactorily why the oyster tends to spawn at full moon, it would be necessary to show how such a time for spawning fits in with the general relation of the oyster to its environment over the whole of its life history; while in order to find out the immediate cause of spawning, it will be necessary to examine critically the spawning habits of oysters under different conditions in different localities in relation to all probable predisposing factors, such as :-

I. Tide: variation in height, accompanied by-

(a) increase and decrease of pressure at successive high and low tides.

(b) increase and decrease of temperature generally at successive low and high tides.

(c) increase and decrease of salinity generally at successive high and low tides.

(d) increase and decrease of other more recondite hydrographical factors, such as $\mathrm{pH}$.

At spring tides the rate of change in the above factors will generally be greatest, so that decrease of pressure, increase of temperature and to a less extent decrease of salinity - will act together.

II. Moonlight : variation in intensity and duration.

Maximum values will occur about new moon spring tides.

III. Food: variation in the amount of (a) available food material, and/or (b) food-intake in the tidal or bi-lunar cycle.

Food may be most abundant and feeding most active during neap tides, but this is not known with accuracy, but in view of the rapid development of the sex-elements ( $\mathbf{6}$ and $\mathbf{9})$ these factors are undoubtedly important.

IV, Temperature: absolute variation.

There can be little doubt that a temperature of about $60^{\circ} \mathrm{F}$. constitutes the lower limiting value for breeding in the oyster. 
V. Sunshine: the variation in duration and intensity of which should not be neglected in a study of an estuarine form: maximum values on the beds would tend to occur at spring tides.

VI. Undetected factors, such as may have operated in the course of evolution, and may or may not now be determinable.

On the Falmouth beds-and in the South of England-low spring tides fall at about midday and midnight, and as is well known the greatest springs occur in the summer time, on the full moon tides. Therefore, the range of variation in $\mathrm{I}, \mathrm{a}, \mathrm{b}$, and $\mathrm{c}$, and probably $\mathrm{d}$, is greatest at full moon tides, but is also great at new moon tides. II has its highest value at full and lowest at new moon tides, while III, a, and probably III, b, are greatest at neap tides, but these are unknown (see 14). IV will normally produce its greatest effect on the spring tides of full and new moon, but is subject to fluctuation, while $\mathrm{V}$ would again tend to have maximum values in shallow water and at low water springs full and new moon.

Now, since dumpy oysters showed a tendency to breed in numbers on both new and full moon tides, as did the normals on the August new moon tide, it would appear that those factors telling principally at the spring tides are chiefly concerned as stimuli causing the oyster to spawn. Thus, it may well be that the rapid rate of change in pressure accompanied by increased temperature at spring tides is sufficient stimulus to cause spawning. On this view it follows that spawning at the full moon tide may be a mere coincidence, and it will be interesting to see what will happen in 1926 when the times of the month at which full and new moons occur will practically have changed places as compared with 1925 . It may be that moonlight or other factors are concerned, but unless the whole of the factors concerned can be obtained and correlated it is unlikely that a critical resolution of the probable stimulus or stimuli can be effected. It is more likely that critical information on the probable stimuli causing spawning will be obtained from a simultaneous study of populations of oysters in widely different localities, or even geographical regions, especially if a locality could be found where full and new moon tides have practically the same range of rise and fall.

\section{On the Frequency in and Proportion of the Oyster Population Spawning.}

The monthly rhythm in the spawning of the oyster may be, and probably is, connected with the period required for the maturation of the gonad. Spärck has recently given experimental data showing that three males rapidly passed into ripe females in from one week to a fortnight 
(9, p. 31) in the summer months. Fox (10) has observed rapid development of eggs in sea-urchins comparable with that seen by Spärck in oysters. The present writer has recorded one case (6) of an oyster spawning as a female, changing into a male, and yet again spawning as a female six weeks after it was last noticed in a male condition.

There is need for extensive experiments on these lines, but some information on the problem may be culled from Figs. 3 and 4 . The maturation of the gonad, however, comprises in the case of females, not only a development of oogonia into ripe eggs, but a period of active feeding to enable the necessary reserves to be accumulated to nourish the developing eggs. It is proposed to discuss this matter fully later, but reference may be made to Fig. 3 , p. 210 , which gives the analysis of the samples of normal oysters for pure ripe females which did not spawn in the weekly batches examined. The percentage of unspawning ripe females added to the total percentage spawning gives the total percentage of females in each sample. The percentage of ripe unspawning females falls off on the whole from a high figure at the beginning of the season to a low figure at the end, but persisted in a small percentage into the winter period. In the same way the total percentage of females shows a gradual falling off through the summer, but the increases observable in the full moon week or the week after are only explicable on the assumption that there is a rapid development of females round about the period of full moon. It is therefore a reasonable assumption that the weeks following full moon constitute a period of preparation of potential females for maturation at about the time of the next full moon, and that in 1925 such a maturation occurred in fair numbers of individuals in the months of June, July, and August, while there is even a small rise at the end of September. At the beginning of the winter an indication of an increase in the percentage of ripening females is shown in Fig. 3, p. 210, and on February 18, 1926, a sample of oysters was found to have the high percentage of $31 \cdot 7$ recognisable ripening females. There is therefore no doubt that at the end of the spring of 1926, the percentage of ripe females will have risen again to the high figure shown in Fig. 3 (nearly 50\%) occurring on July 1, 1925. Thus it is clear that the maturation period of the majority of female oysters must occur in the winter and early spring.

The writer has now obtained by experiment a reasonable number of oysters which have been shown to experience four changes of sex in a period of twelve to thirteen months, but in view of the results shown in Fig. 3, it is probable that in a summer like 1925 four changes of sex may occur in one and the same season. Indeed assuming, as we now have reason to, that the constituents of the oyster population were similar, it can be shown that more than $100 \%$ of the oysters spawned 
as females, a result which means that some oysters spawned as females twice, with the corollary that they must have experienced also two phases of maleness. Let only the samples taken during the weeks after full moon in July, August, September, and October be considered, then respectively $33,18,22$, and $1.5 \%$ were taken carrying embryos, giving a total of the population-disregarding all other samples and those breeding before July - of $110 \%$ breeding as females. In the same way it can be shown that at least $100 \%$ of the dumps must also have spawned. The actual figure might be very much higher than this, and a large proportion of the population must, on the assumption made, which we have seen is reasonable, have spawned twice as females. This result is surprising, perhaps, but not at all unreasonable in view of what is known of the breeding of other marine animals.

\section{Other Marine Animals Spawning at or near Full Moon.}

Fox (4) found the Suez sea-urchins (Centrechinus setosus) [Diadema] to breed at full moon, and one and the same individual to breed in successive full moons, but in these sea-urchins there is no known change of sex. The occurrence of breeding in marine animals in relation to varying phases of the moon is also discussed at length by Fox, who notes that in no case has a satisfactory explanation been offered of an apparent relation between some phase of the moon and breeding in various types of marine animals, including worms, molluses, sea-urchins and a fish. In most cases the influence of the tides in connexion with the moon is suspected, but in the locality where the Suez sea-urchins occur, Fox showed that there is actually more tide at new than at full moon. It would seem reasonable, therefore, to investigate more fully the possible influence of moonlight itself, even though this factor does not appear on the surface to be essentially concerned. When the case of the oyster has been more fully investigated, it will be possible to make definite experiments on a large scale, as the oyster is a sedentary animal and amenable to experimental work.

\section{Ancient Naturalists on the Condition of the Oyster in Relation to the Moon's Phases.}

It is fitting to conclude this paper with quotations long ago culled by Philpots (3, pp. 44-52) from the writings of the ancient naturalists. Pliny states " that generally speaking (oysters) increase in size with the increase of the moon " and similar quotations are given from Lucilius, Manilius, Horace, and Cicero (loc. cit., p. 50), while a quotation of Annianus is given with reference to the condition of oysters after full moon, namely, " the moon is now in truth waning, and on that account the oyster, like 
other things, is lean and void of juice." Fox (4) gives also similar quotations from Aristotle and others. It is a fact of great interest that Fox began his successful investigation of breeding in the Suez seaurchins as a result of hearing the belief widely held at the present day in the East of the effect of the moon on not only certain marine animals, but also certain vegetables. An interesting general discussion is given by Fox. Philpots also observes (loc. cit., p. 51) that Faber (11) records that even at the present day the Tarentines declare that oysters are "fattest during the full moon." In view of what has been described above in the case of Fal Estuary oysters, we may now reasonably expect a demonstration of a maximum spawning of-at least, normal - oysters in the Tarento beds in the south of Italy and elsewhere at about the time of full moon.

\section{The Economic Aspect of the Results Obtained.}

The economic aspect of some of the results noted above has been partly dealt with (12), and it has already been shown that cultch can be laid much later in the year than is customary with a prospect of an economic return in a collection of late spat. It has been shown that on the oyster beds in the Thames Estuary spat caught later in the year than July had grown to a size of upwards to $1 \frac{1}{4}$ inches by the following July, and that spat taken as late as August in the poor year of 1923 attained a good shape and a size of upwards to one inch by the following July in the sea. In a warm year, therefore, and indeed also in normal years, it follows that since a maximum of spawning may be expected at full moon tides, the cultch should not be laid in one great batch, but should be laid in separate batches at intervals of about one month, beginning in the week after the first full moon at which a normal spawning occurs. In this way can be prevented a great waste of cultch by its becoming slimy or unclean from overgrowth. Where cultch is cheap a batch may be sprinkled over the grounds in a warm summer, even in September, especially on the Fal Estuary beds, with a prospect of an economic return in settled spat. In this connexion it is of interest to record that during risits to the Truro beds in October, 1925, the writer found on a fair proportion of shells of recently dead oysters tiny spat only a few millimetres in diameter, which had probably settled during the month of September. Mr. J. W. Tabor sends information by letter that he also found similar tiny spat on the beds off Whitstable late in the year 1925.

The observation of Mr. French (see p. 217) that settled spat may begin to fall in the sea ten days to one fortnight after the first black-sick oyster is seen on the beds-Hagmeier (13) obtained similar results in pit experiments - is of great value in estimating the correct time to put out in the sea the first batches of cultch, and as it has been shown above that a maximum number of black-sick oysters is likely to occur in the week 
after full moon, the fall of spat may be expected to begin normally on the following new moon tides. On economic grounds it is advisable, however, that extended observations on spawning in relation to the moon's phases should be carried on over a series of years to test fully the probability of a maximum spawning occurring at any fixed period. In this way cultch can eventually be laid intelligently and with a greater prospect of an economic return, and a replenishment of our oyster beds with spat.

\section{ACKNOWLEDGMENTS.}

Acknowledgment is due to the Truro Corporation (River Committee) for supplying oysters during the summer for the observations on spawning; and to the Falmouth Corporation (Harbour Committee) for a sample of oysters in August; and the writer is especially indebted to Professor P. R. Awati for assistance in examining the first four samples from Truro; to Mr. Louis French for permission to quote his valuable field experience, and in many ways to the Directors of the Tollesbury and Mersea Native Oyster Company.

\section{SUMMARY.}

During 1925 dumpy oysters spawned in a high proportion on the Fal beds, and although not such heavy breeders as normal oysters, they are undoubtedly valuable in forming a stable spawning stock for replenishing the beds in the future.

Nearly every normal and dumpy oyster above a size of 2 to $2 \frac{1}{2}$ inches produced at least one batch of spawn in 1925. Since dumps increase in proportion on the beds as over-fishing occurs, they form a natural breeding reserve for repopulating the beds in favourable years, as there is no adequate reason to suppose that the larvæ of dumps are unhealthy. Weekly samples of oysters examined closely during the summer of 1925 for the percentage of spawning females and ripe but unspawned females show-

(1) that the population as a whole gave maximal percentages in spawn in the weeks after the July and September full moons.

(2) that normal oysters showed three maximal percentages in spawn in the weeks after the July, August, and September full moons.

(3) that dumpy oysters spawned more irregularly.

A certain amount of spawning occurred at other times than full moon. There is good reason to believe that the population of oysters sampled is an approximately uniform one in spawning behaviour. Hence there is little doubt that oysters showed a marked tendency in the Fal Estuary in 1925 to breed rhythmically at about the time of full moon. 
The summer of 1925 was very favourable for the spawning of oysters, except for a short spell of cold weather in early August, and spawning was subjected to relatively little interference for English weather conditions.

An analysis of the spawning oysters into those with young embryos and those with mainly shelled larvæ brings out the fact statistically that oyster larvæ under natural conditions are retained in the mantle cavity a period of only 1 to $1 \frac{1}{2}$ weeks from the date of their extrusion as fertilised eggs from the parent. This observation is in concordance with extended field observations and experimental evidence of the attainment of the black-sick stage by an oyster in 5 to 7 days from the date of spawning.

The probable causes of spawning at full moon are discussed, and of the immediate stimuli likely to produce spawning decrease of pressure with increase of temperature at low water are considered the most likely factors, without, however, excluding other factors which cannot be fully investigated in the absence of data. It is pointed out that a full explanation of spawning at full moon must explain this phenomenon in relation to the main facts of the life-history of the oyster.

Ripe females decreased in numbers during the summer from about $50 \%$ to about $5 \%$, while recognisable ripening females increased in the following autumn and winter from about $4 \%$ to more than $30 \%$ already in February.

The chief period for maturation of females is in the winter, but a proportion may mature also in the summer.

It is shown that on the assumption that a uniform population was sampled all through the summer, the normal and to a less extent the dumpy oysters must have spawned in fair numbers twice as females - and consequently once and possibly twice as males during the course of the summer. Attention is drawn to statements by Aristotle and Pliny and other ancient naturalists, and by Tarentines at the present day on the correlation between the condition of Mediterranean oysters and the moon's phases, and the probability of truth in these statements as the result of the observations recorded above.

The extended spawning season here demonstrated adds weight to experiments carried out by the writer with late cultch, showing that economic returns may be expected from layings of cultch made far later in the year than is the custom.

Proof of a maximum spawning time, as at full moon, if confirmed over a period of years, would allow the oyster-producer to lay cultch at the correct time to catch a maximum of spat with a minimum of waste cultch, and waste oyster larvæ. 


\section{LITERATURE.}

1. Orton, J. H. Report on a Survey of the Oyster Beds in the Estuary of the Fal (Nov., 1924) with Notes on the Biology of the Oyster (in Typescript). A summary of the above-mentioned report was printed by the Truro and Falmouth Corporations. Falmouth, 1925.

2. Bell, A. British Oysters: Past and Present. Essex Naturalist XIX, Plate XII, Fig. 3, 1921.

3. Philpots, J. R. Oysters and all about them. London, 1890.

4. Fox, H. M. Lunar Periodicity in Reproduction. Proc. Roy. Soc. B., Vol. 95, 1923, p. 523.

5. Admiralty Chart, No. 32, Falmouth Harbour.

6. Orton, J. H. Sex-change and Breeding in the Native Oyster (O. edulis). Nature, 114, Aug. 9, 1924, p. 191.

7a. Weekly Weather Report of the Meteorological Office, 1925, p. 127.

7b. Monthly Weather Report of the Meteorological Office, 1925, p. 107.

8. Orton, J. H. Oyster Mortality Investigations, 1920-21. Fisheries Invest., II, VI, No. 3, pp. 26-29, 1923, London (1924).

9. Spärck, R. Studies on the Biology of the Oyster $(O$. edulis) in the Limfjord, with special reference to the Influence of Temperature on the Sex-change. Report of the Danish Biological Station, XXX, 1924 (1925).

10. Fox, H. M. The Spawning of Echinoids. Proc. Camb. Phil. Soc. Biology, I, 2, p. 74, 1924.

11. Faber, G. S. The Fisheries of the Adriatic. London, 1883.

12. Orton, J. H. The Production of Oysters (O. edulis) on English Beds in Relation to new Observations on Breeding Phenomena. Nature, Nov. 7,1925 , p. 673.

13. HaGmeier, A. Ueber die Fortpflanzung der Auster und die fiskalischen Austerbänke. Wiss: Meeres: Helgoland, XI, 1916.

14. Savage, R. E. The Food of the Oyster. Fishery Invest., II, VIII, No. 1, 1925. London. 
